\title{
Endoscopic ultrasound-guided coil and glue for treatment of splenic artery pseudo-aneurysm: new kid on the block! $\square$
}

\section{다(1) $(9)$}

\author{
Authors \\ Institutions \\ 1 Department of Gastroenterology, Sanjay Gandhi \\ Postgraduate Institute of Medical Sciences, Lucknow, \\ Uttar Pradesh, India \\ 2 Department of Gastroenterology, Jaswant Rai Speciality \\ Hospital, Meerut, Uttar Pradesh, India
}

Praveer Rai ${ }^{1}$, Harish KC ${ }^{1}$, Amit Goel ${ }^{1}$, Rakesh Aggarwal ${ }^{1}$, Malay Sharma ${ }^{2}$

submitted 4.2.2018

accepted after revision 9.4.2018

Bibliography

DOI https://doi.org/10.1055/a-0608-4402 |

Endoscopy International Open 2018; 06: E821-E825

(c) Georg Thieme Verlag KG Stuttgart · New York ISSN 2364-3722

Corresponding author

Dr. Praveer Rai, Additional Professor, Department of

Gastroenterology, Sanjay Gandhi Postgraduate Institute of

Medical Sciences, Lucknow 226014 India

Fax: +91-522-2494428

praveer_rai@yahoo.com

\section{ABSTRACT}

Background and study aims Pseudoaneurysm most commonly involves the splenic artery and is conventionally treated with angioembolization or surgery. Herein we describe six patients with splenic artery pseudoaneurysm who were treated using a new technique of endoscopic ultrasound (EUS)-guided glue and coil injection.

Patients and methods Six patients (median age 36.7, range: $19-60, \mathrm{M}: \mathrm{F}=5: 1$ ) with splenic artery pseudoaneurysm who had failed angiographic embolization underwent EUS-guided transgastric injection of coil and glue injection between July 2016 and September 2017.

Results The diameter of the splenic artery pseudoaneurysms varied from $2.5 \mathrm{~cm}$ to $6.5 \mathrm{~cm}$. The size $(8,14$ and $16 \mathrm{~mm}$ ) and number ( 1 to 5 ) of coils and amount of glue $(1-2 \mathrm{~mL})$ injected all were greater in larger aneurysm. All six patients had complete occlusion of the pseudoaneurysm as determined by using computed tomography at 4 weeks and EUS at 12 weeks. No complication was encountered.

Conclusion EUS-guided coil and glue injection for obliteration of splenic artery pseudoaneurysm is a feasible, highly effective and safe technique.

\section{Introduction}

Splenic artery aneurysms (SAA) are the most common true aneurysms, comprising $50 \%$ to $75 \%$ of all visceral artery aneurysms (VAA). Prevalence of SAAs varies between $0.04 \%$ and $0.10 \%$ at autopsy and $0.8 \%$ on nonselective angiogram [1].

Pseudoaneurysms occur secondary to infectious, inflammatory or iatrogenic causes, are usually asymptomatic and are therefore detected as incidental findings during abdominal imaging. They are mostly saccular and situated in the mid to distal splenic artery [2]. The rate of rupture is higher than true aneurysm and is around $3 \%$ to $20 \%$ [3].

VAAs can be treated by surgery or radiographic intervention depending on their location and configuration and the patient's comorbidities and clinical condition. While some authors suggest that all splanchnic aneurysms should be treated, others propose that conservative management also has a place $[4,5]$. Single-institutional series with more than 50 patients are uncommon [5].
We describe here a series of six patients with splenic artery pseudoaneurysm in whom we achieved successful obliteration using a new technique of endoscopic ultrasound (EUS)-guided glue and coil injection.

\section{Patients and methods}

\section{Patients}

Case records of six adult (18 years or older) patients with splenic artery pseudoaneurysm who underwent EUS-guided placement of coil and glue in the pseudoaneurysm over a 1-year period (Jul 2016 to Sep 2017) were reviewed. Three patients had a history of gastrointestinal bleeding (hematemesis 2, melena 1) and the remaining three were asymptomatic. All six patients had failed radiographic angiographic embolization due to inability to catheterize the tortuous splenic artery.

Clinical details, including age, gender, co-existing conditions, and presenting symptoms and hemodynamic status at the time of treatment were recorded. Information on charac- 

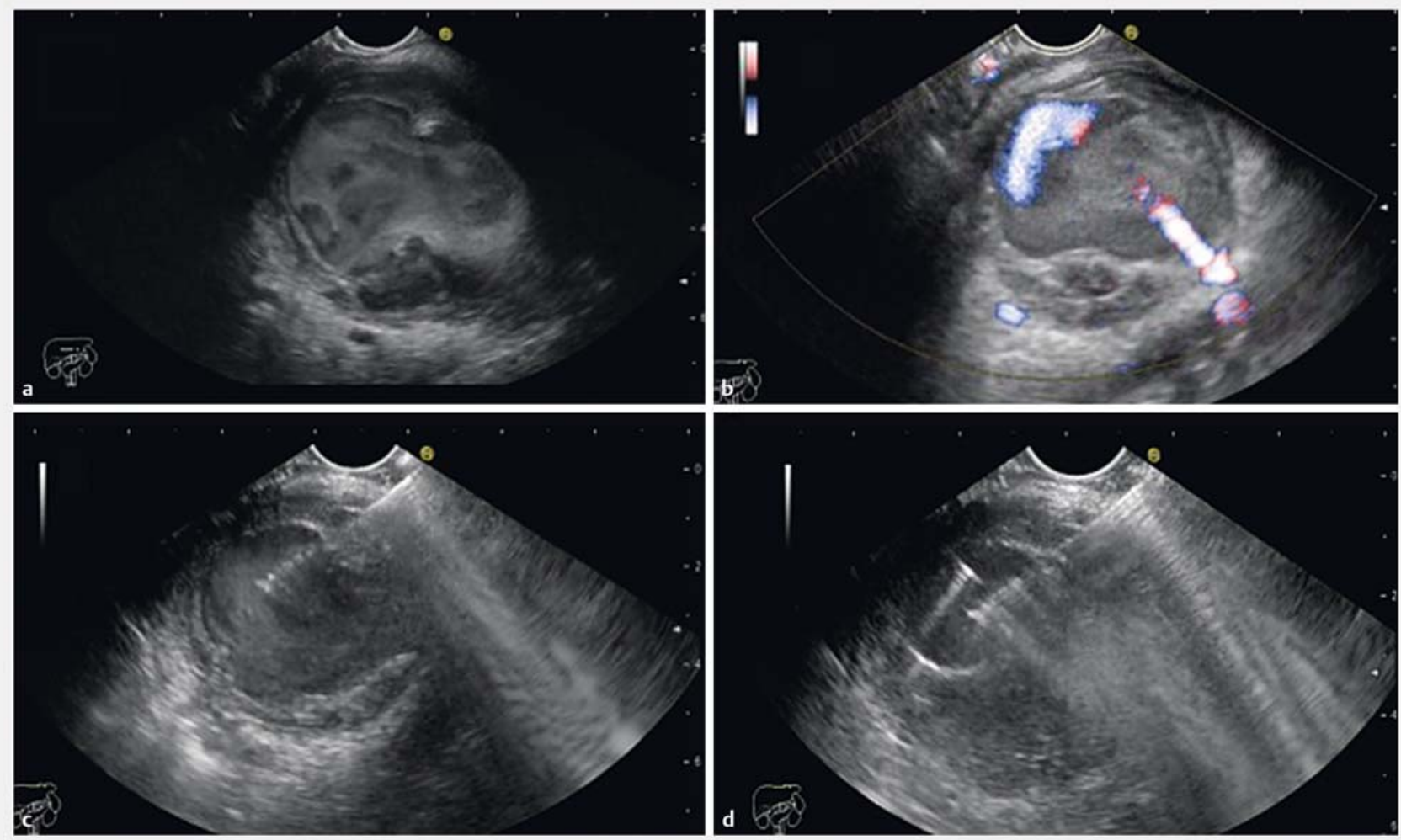

- Fig. 1 a Large splenic artery pseudoaneurysm. b Color flow in the pseudoaneurysm. c 19 gauge fine-needle aspiration needle used to puncture the splenic artery pseudoaneurysm. $\mathbf{d}$ Coil injected into the pseudoaneurysm.

teristics of the aneurysms, including size, localization, rupture and anatomic variation, was also extracted. All patients signed an informed consent for this experimental treatment. Contraindications included hemodynamic instability, coagulopathy, and general contraindication for endoscopic procedures.

\section{EUS-guided coil and glue}

All procedures were performed by one endoscopist (PR) and were done under propofol sedation and after a prophylactic dose of ceftriaxone ( $1 \mathrm{~g}$ intravenously). A linear echoendoscope (GF UCT 180; Olympus, Tokyo, Japan) was positioned in the stomach and the splenic artery pseudoaneurysm was identified using color Doppler. The pseudoaneurysm was punctured using a 19-gauge EUS-guided fine-needle aspiration (FNA) needle (Expect; Boston Scientific, United States), while taking care to avoid any intervening blood vessels ( $\mathbf{F i g}$. 1a, > Fig. 1 b, $>$ Video 1$)$.

After puncturing the aneurysm, the stylet of the needle was withdrawn and embolization coils (Cook Medical Inc., Bloomington, Indiana, United States) were pushed through the FNA needle into the aneurysm followed by injection of glue ( $n$ butyl-2-cynoacrylate) ( Fig.1c, $>$ Fig.1d, > Fig.2a). The diameter $(8,14$ or $16 \mathrm{~mm})$ and number of the coils used and amount of glue injected varied with size of the pseudoaneurysm. In general, one $8-\mathrm{mm}$ coil and $1 \mathrm{~mL}$ of glue was used if the pseudoaneurysm size was up to $3 \mathrm{~cm}$ and a 14 or $16 \mathrm{~mm}$ coil and $2 \mathrm{~mL}$ of glue was used if it was larger than $3 \mathrm{~cm}$. More coils were injected if the aneurysm was not obliterated. The end-point of treatment was complete obliteration of the aneurysmal sac, as confirmed by Doppler ( Fig. $2 \mathbf{b}$ ). Computed tomography (CT) images before and after EUS-guided coil place-

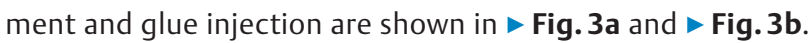

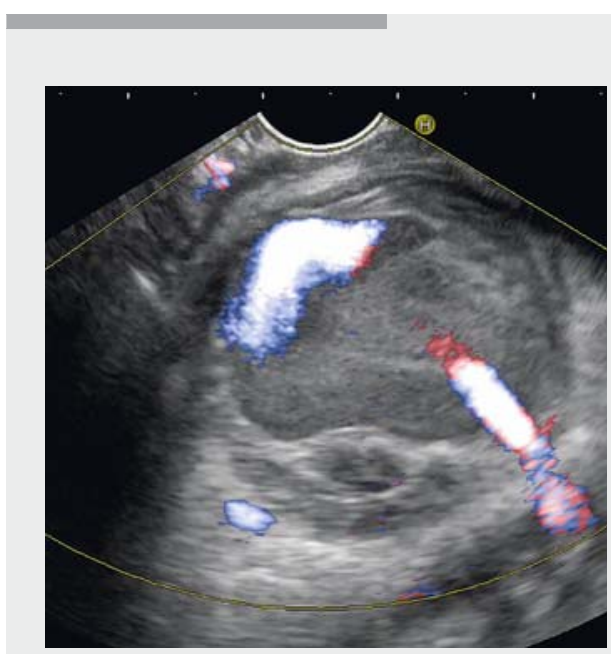

$\checkmark$ Video 1 EUS-guided coil and injection done in a large splenic artery pseudoaneurysm using a 19-gauge fine-needle aspiration needle leading to complete obliteration of aneurysm. 

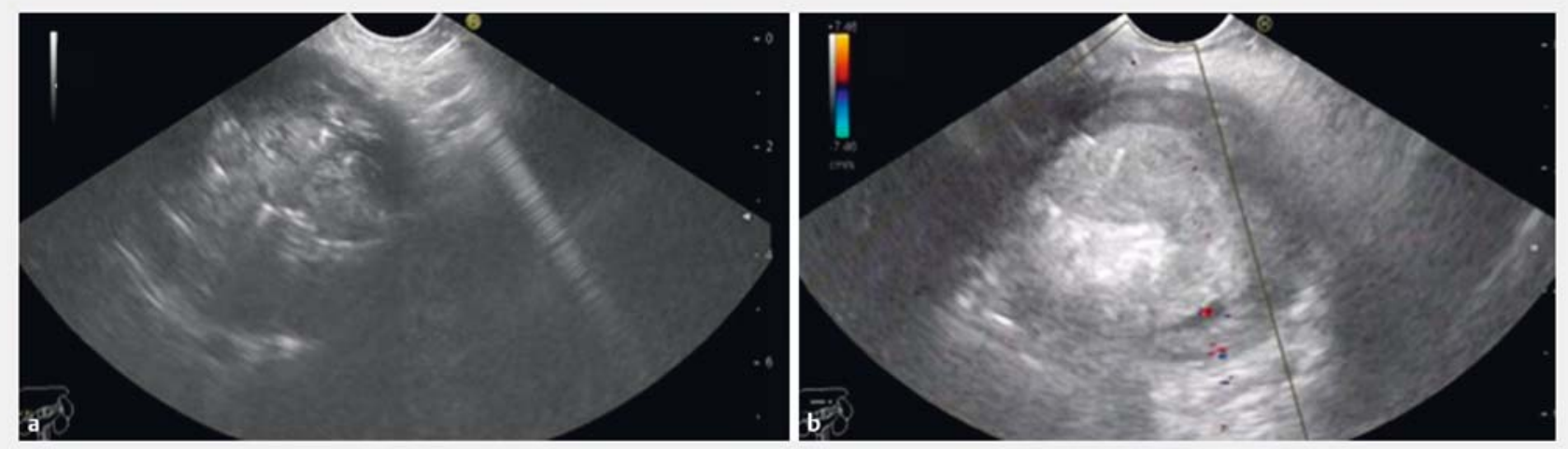

- Fig. 2 a Glue injected into the pseudoaneurysm. b No flow in the pseudoaneurysm at color Doppler examination.
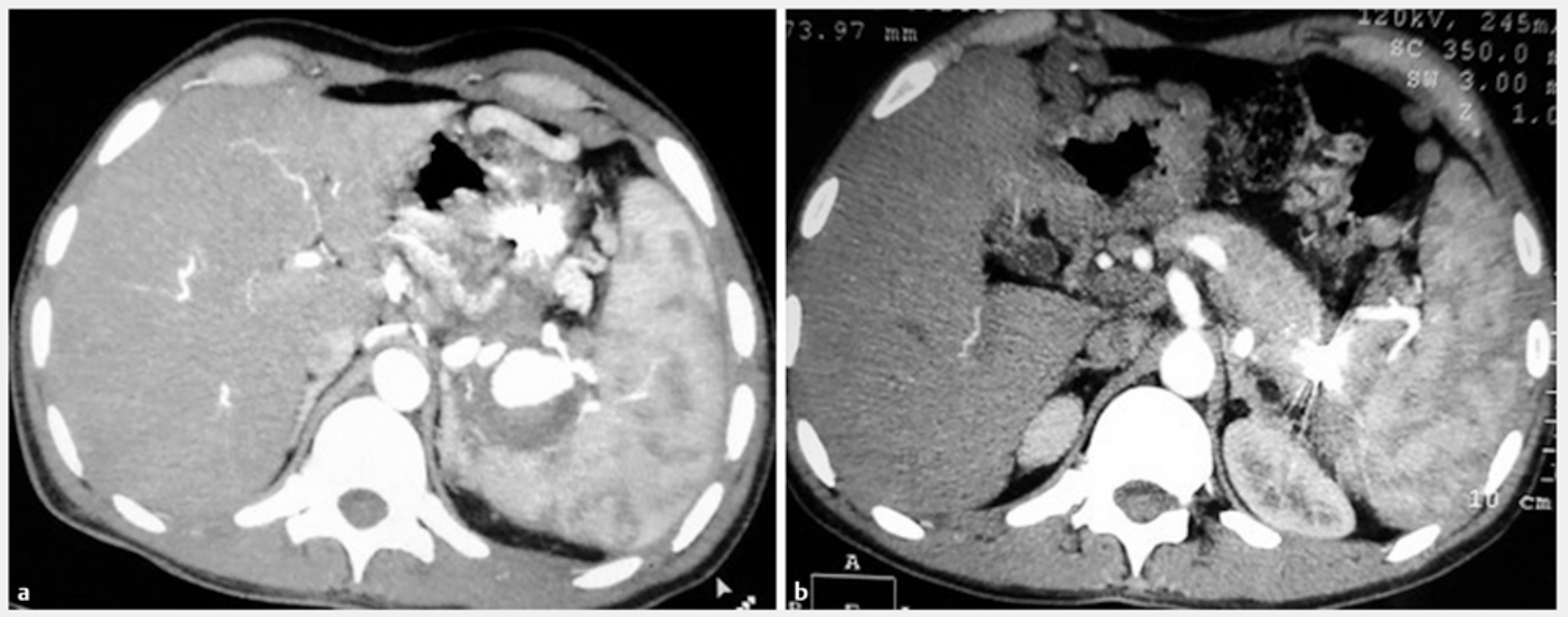

- Fig. 3 a CT angiography before EUS-guided coil and glue. b CT angiography 3 months after EUS-guided coil and glue.

\section{Follow up}

An EUS was done 2 days after the procedure to confirm obliteration of the pseudoaneurysm ( $\downarrow$ Video 2 ). More coils and glue were placed if there was still flow within the pseudoaneurysm. All patients were followed up on outpatient basis at weeks 4 and 12. At each follow-up, a clinical evaluation was done, hemoglobin level was measured and any adverse events (AEs) were recorded. CT angiography was done at 4 weeks and an EUS was done at 12 weeks to confirm obliteration of the pseudoaneurysm.

\section{Outcome measures}

The procedure was considered to be a technical success if the coil as well as glue could be injected into the pseudoaneurysm. Clinical success was defined as complete obliteration of the pseudoaneurysm at 12 weeks without any fall in hemoglobin. Any AEs, such as occurrence of abdominal pain, fever, hemorrhage or death, which could be attributed to the procedure were recorded.

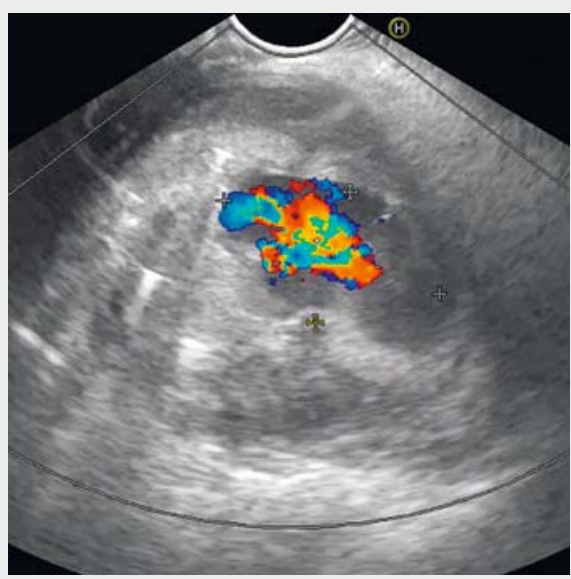

$\nabla$ Video 2 EUS done 48 hours after first session showed flow in the aneurysm and repeat coil and glue injection was done. 
- Table 1 Baseline characteristics, technique, success and follow-up of splenic artery pseudoaneurysm.

\begin{tabular}{|c|c|c|c|c|c|c|c|c|c|}
\hline \multirow{2}{*}{$\begin{array}{l}\text { Pt. } \\
\text { ID }\end{array}$} & \multirow{2}{*}{$\begin{array}{l}\text { Age } \\
\text { and } \\
\text { sex }\end{array}$} & \multirow{2}{*}{$\begin{array}{l}\text { Aneur- } \\
\text { ysm size } \\
(\mathrm{cm})\end{array}$} & \multirow{2}{*}{$\begin{array}{l}\text { Session } \\
\text { number }^{1}\end{array}$} & \multicolumn{3}{|c|}{ Technique } & \multirow{2}{*}{$\begin{array}{l}\text { Technical } \\
\text { success }\end{array}$} & \multirow[t]{2}{*}{ Follow-up imaging ${ }^{2}$} & \multirow{2}{*}{$\begin{array}{l}\text { Clinical } \\
\text { success }\end{array}$} \\
\hline & & & & $\begin{array}{l}\text { Coil size } \\
(\mathrm{mm})\end{array}$ & $\begin{array}{l}\text { Number } \\
\text { of coils }\end{array}$ & $\begin{array}{l}\text { Glue volume } \\
(\mathrm{mL})\end{array}$ & & & \\
\hline 1 & $33 \mathrm{M}$ & $2.0 \times 2.5$ & 1 & 8 & 1 & 1 & Yes & Complete obliteration & Yes \\
\hline 2 & $37 \mathrm{M}$ & $2.0 \times 2.5$ & 1 & 8 & 1 & 1 & Yes & Complete obliteration & Yes \\
\hline 3 & $19 \mathrm{M}$ & $3.0 \times 3.0$ & 1 & 8 & 1 & 1 & Yes & Complete obliteration & Yes \\
\hline \multirow[t]{2}{*}{4} & \multirow[t]{2}{*}{$60 \mathrm{M}$} & \multirow[t]{2}{*}{$4.2 \times 2.7$} & 1 & 16 & 2 & 1 & \multirow[t]{2}{*}{ Yes } & \multirow[t]{2}{*}{ Complete obliteration } & \multirow[t]{2}{*}{ Yes } \\
\hline & & & 2 & 14 & 1 & 1 & & & \\
\hline \multirow[t]{2}{*}{5} & \multirow[t]{2}{*}{$46 \mathrm{M}$} & \multirow[t]{2}{*}{$5.5 \times 5.6$} & 1 & 16 & 3 & 1 & \multirow[t]{2}{*}{ Yes } & \multirow[t]{2}{*}{ Complete obliteration } & \multirow[t]{2}{*}{ Yes } \\
\hline & & & 2 & 16 & 2 & 1 & & & \\
\hline \multirow[t]{2}{*}{6} & \multirow[t]{2}{*}{$25 \mathrm{~F}$} & \multirow[t]{2}{*}{$6.0 \times 6.5$} & 1 & 16 & 3 & 1 & \multirow[t]{2}{*}{ Yes } & \multirow[t]{2}{*}{ Complete obliteration } & \multirow[t]{2}{*}{ Yes } \\
\hline & & & 2 & 16 & 2 & 1 & & & \\
\hline
\end{tabular}

\section{Results}

\section{Patient characteristics}

All six patients (median age: 36.7 [range:19-60] years, 5 men) with splenic artery pseudoaneurysm had underlying chronic pancreatitis. All patients underwent EUS-guided coil and glue injection after an attempt at radiologic angioembolization had failed ( $\triangleright$ Table 1 ).

\section{Success rates}

EUS-guided coil and glue injection was technically successful in all six patients. Three patients with aneurysm smaller than $3 \mathrm{~cm}$ needed one $8-\mathrm{mm}$ coil and $1.0 \mathrm{~mL}$ of glue each for complete obliteration. EUS done after 48 hours showed obliterated aneurysm in all three patients.

One patient with a large $4.2 \times 2.7-\mathrm{cm}$ pseudoaneurysm needed two coils $(16-\mathrm{mm})$ along with $1.0 \mathrm{~mL}$ of glue in the first session. EUS done after 48 hours showed a patent aneurysm. Therefore, one more $14-\mathrm{mm}$ coil was placed and $1.0 \mathrm{~mL}$ of glue was injected ( $\triangleright$ Table 1 ).

Two patients with aneurysms larger than $5 \mathrm{~cm}$ received three $16-\mathrm{mm}$ coils and $1 \mathrm{~mL}$ of glue each in the first session. EUS at 48 hours showed a patent aneurysm in both these patients, necessitating injection of two additional $16-\mathrm{mm}$ coils and $1 \mathrm{~mL}$ of glue in each case to achieve complete obliteration.

\section{Adverse events}

No patient had any procedure-related AE. There was no procedure-related death.

\section{Follow-up}

In all six patients, follow up EUS at 4 weeks and CT angiography at 3 months did not show any flow in the pseudoaneurysm.

\section{Discussion}

In our experience, attempt at EUS-guided injection of coil and glue was associated with technical and clinical success in all six patients with splenic artery pseudoaneurysm. Patients with smaller aneurysms achieved complete obliteration after only one session whereas those with larger aneurysms needed two sessions each. Also, the number and size of the coils and volume of glue used were larger for larger pseudoaneurysm. Aneurysms up to $3 \mathrm{~cm}$ needed only one coil each, whereas larger ones $(3-5 \mathrm{~cm})$ needed four coils, and those with diameter exceeding $5 \mathrm{~cm}$ needed five coils each. No patient developed any complication. Pseudoaneurysm remained obliterated during 12-week follow-up.

Splenic artery pseudoaneurysms are potentially fatal and hence treatment is recommended if these exceed $2 \mathrm{~cm}$ in diameter, are increasing in size, are associated with inflammation, are symptomatic or occur in pregnant women or individuals with portal hypertension [6].

Treatment options for splenic artery pseudoaneurysms include surgery and an endovascular approach. Surgery carries a $1 \%$ to $3 \%$ risk of mortality and $9 \%$ to $25 \%$ risk of perioperative complications arising primarily from splenic or pancreatic injury [7]. By comparison, endovascular therapy is associated with lower morbidity and mortality and is thus the preferred treatment. The success rate for endovascular embolization is $95 \%$ and complications include technical failure to catheterize the artery, arterial thrombosis or embolism resulting in organ infarctions or abscesses, coil migration, aneurysm recurrence, and hematoma or pseudoaneurysm at the arterial puncture site [7, 8]. Minor complications (abdominal pain, fever) may follow endovascular repair as a manifestation of postembolization syndrome (PES) $[7,8]$. 
EUS-guided therapy of splenic artery pseudoaneurysm is an evolving procedure with only a few published cases [9]. It primarily involves targeting the pseudoaneurysm via the transgastric route and obliterating it by injecting thrombin, coil and/or glue. Doppler confirms the presence of aneurysm and absence of flow after obliteration.

EUS-guided coil and glue injection was technically and clinically successful in all six patients. This compares well with the $95 \%$ success rate for the endovascular approach [6]. The number of sessions needed was two in patients with pseudoaneurysm exceeding $3 \mathrm{~cm}$ in diameter and one in patients with pseudoaneurysm smaller than this. The second session could be safely done in all patients.

None of the patients with EUS-guided injection developed post-embolization syndrome, an advantage over the endovascular approach. In a study by Lakin et al, three (6\%) of 49 patients with splenic artery aneurysm treated by the endovascular approach needed intervention for splenic abscess and 5 (10\%) patients developed post-procedure upper abdominal pain with or without a documented splenic infarct. In addition, nine (18.4\%) patients had some evidence of postembolization splenic infarction in the absence of any symptoms or sequelae [10]. Patients with distal SAAs were at a higher risk for PES and/or asymptomatic splenic infarction. There was no rupture or mortality in patients treated with treated with EUS-guided coil and glue.

\section{Conclusion}

To conclude, EUS-guided coil and glue injection for splenic artery pseudoaneurysm is feasible with high technical and clinical success rates, and without any AEs and can be repeated safely if needed. Considering the rarity of the disease and the technical expertise needed, there is need for a multicenter study to further assess the role of this therapy in treatment of splenic artery pseudoaneurysms.

\section{Competing interests}

None

\section{References}

[1] Berceli SA. Hepatic and splenic artery aneurysms. Semin Vasc Surg 12 2005; 18: 196-201

[2] Nosher JL, Chung J, Brevetti LS et al. Visceral and renal artery aneurysms: A pictorial essay on endovascular therapy. RadioGraphics 2006; 26: $1687-1704$

[3] Cordova AC, Sumpio BE. Visceral artery aneurysms and pseudoaneurysms - Should they all be manage by endovascular techniques? Ann Vasc Dis 2013; 6: 687-693

[4] Muscari F, Barret A, Chaufour X et al. Management of visceral artery aneurysms. Retrospective study of 23 cases. Ann Chir 2002; 127: $281-288$

[5] Saltzberg SS, Maldonado TS, Lamparello PJ et al. Is endovascular therapy the preferred treatment for all visceral arteryaneurysms? Ann Vasc Surg 2005; 19: 507- 515

[6] Hogendoorn W, Lavida A, Hunink MG et al. Open repair, endovascular repair, and conservative management of true splenic artery aneurysms. J Vasc Surg 2014; 60: 1667 - 1676

[7] Abbas MA, Stone WM, Fowl RJ et al. Splenic artery aneurysms: two decades experience at Mayo Clinic. Ann Vasc Surg 2002; 16: 442 - 449

[8] Sessa C, Tinelli G, Porcu P et al. Treatment of visceral artery aneurysms: description of a retrospective series of 42 aneurysms in 34 patients. Ann Vasc Surg 2004; 18: 695-703

[9] Rai P, Bhera B, Sharma M. First report of successful treatment of splenic artery pseudoaneurysm with endoscopic ultrasound-guided coil and glue. Endoscopy 2017; 49: E179-E180

[10] Lakin RO, Bena JF, Sarac TP et al. The contemporary management of splenic artery aneurysms. J Vasc Surg 2011; 53: 958 - 964 